\title{
Hesperidin associated with continuous and interval swimming improved biochemical and oxidative biomarkers in rats
}

David Michel de Oliveira, Grace Kelly Zanotti Simoes Dourado and Thais Borges Cesar ${ }^{*}$

\begin{abstract}
Background: Citrus flavonoids, such as hesperidin, have shown therapeutic properties that improve hyperglycemia and insulin resistance, and decrease blood serum lipids and inflammation. The current investigation studied the effects of hesperidin supplementation associated with continuous and interval swimming on the biochemical parameters (glucose, cholesterol and triglycerides), and oxidative stress markers (TBARS and DPPH) in rats.

Methods: The animals $(n=60)$ were randomly divided in six groups: negative $(C)$ and positive control $(C H)$ for hesperidin supplementation, and continuous or interval swimming without (CS and IS) or with hesperidin supplementation (CSH and ISH). Hesperidin was given by gavage for four weeks (100 mg/kg body mass) before the exercise. Continuous swimming was performed for 50 min with loads from $5 \%$ to $8 \%$ of body weight from the first to fourth week, while interval swimming training was performed for 50 min in sessions of 1 min of swimming followed by 2 min of resting, carrying loads from 10\% to 15, 20 and 25\% from the first to fourth week. At the end of the experiment, blood serum samples were draw to perform analysis of glucose, total cholesterol, HDL-C and triglycerides. Oxidative biomarkers were evaluated by lipid peroxidation (TBARS) and antioxidant capacity assay (DPPH) of the blood serum.
\end{abstract}

Results: There was a continuous decline of serum glucose from C (100\%) > CH (97\%) > CS (94\%) > CSH (91\%, p <.05), IS $(87 \%, \mathrm{p}<.05)>$ ISH $(80 \%, \mathrm{p}<.05)$, showing a combined beneficial effect of hesperidin and swimming. Also, continuous or intermittent swimming with hesperidin supplementation lowered total cholesterol $(-16 \%, p<.05)$, LDL-C $(-50 \%$, $p<0.05)$ and triglycerides $(-19 \%, p<0.05)$, and increased HDL-C $(48 \%, p<.05)$. Furthermore, hesperidin enhanced the antioxidant capacity on the continuous swimming group $(183 \%, \mathrm{p}<.05)$ and lowered the lipid peroxidation on the interval swimming group $(-45 \%, \mathrm{p}<.05)$.

Conclusions: Hesperidin supplementation per se, or in combination with swimming exercise protocols, improved the biochemical profile and antioxidant biomarkers evidencing that the use of flavanones may enhance the health benefits promoted by exercise.

Keywords: Hesperidin, Continuous swimming, Interval swimming, Blood serum biomarkers, Antioxidant, Rat

\footnotetext{
* Correspondence: tcesar@fcfar.unesp.br

Department of Food and Nutrition, School of Pharmaceutical Sciences,

UNESP, Rodovia Araraquara-Jau, km 1, Araraquara 14802-901, Brazil
} 


\section{Background}

Regular practice of exercise has been recommended by health-care professionals as a coadjuvant element and a protective factor to control metabolic, hormonal, and cardiovascular parameters associated with the development of chronic diseases [1]. Variables such as type, quantity and intensity of the exercise can have crucial metabolic and physiologic effects. In this sense, continuous exercise is characterized by moderate to intense exercise of extended duration using fatty acids as the predominant energy source. On the other hand, interval exercise is defined as high intense exercise with passive or active pauses using glucose as the predominant source of energy [2]. Continuous and interval exercise protocols have been used as a strategy to control glucose and lipids of blood stream [3-7].

Exhaustive exercise and overtraining may increase the rate of free radical production to a level which exceeds the capacity of the cellular defense system, and consequently impairs the cell viability and initiates the damage on the skeletal muscle and promotes inflammation [8]. To minimize these negative effects, antioxidant supplements can be taken to attenuate the side-effects of exercise, and flavonoids in general can be used to improve the antioxidant capacity $[9,10]$. Previous studies in humans and animals, especially rodents, have demonstrated that hesperidin and its metabolites decrease blood serum glucose and lipids and neutralize markers of oxidative stress [11-14]. Although a body of evidence has shown these benefits, most of the mechanisms are still being explored [9,15-18].

The purpose of this study was to analyze the interaction of hesperidin and continuous or interval exercises, evaluated by potential changes on biochemical parameters, as glucose, cholesterol and triglycerides, and biomarkers of oxidative stress in rats, as lipid peroxidation (TBARS) and antioxidative capacity (DPPH). We compared the blood levels of glucose and lipids in rats submitted to continuous exercise and interval swimming protocols, and we also evaluated two oxidative biomarkers for both protocols plus the effect of hesperidin supplementation. The following hypotheses were tested: (1) The improvement of the blood serum variables by the continuous and interval swimming with hesperidin supplementation; and (2) the reduction of oxidative stress rate, promoted by continuous and interval exercises, by the antioxidant effects of hesperidin supplementation.

\section{Methods}

\section{Reagents}

Hesperidin supplement was obtained by Hyashibara, Japan, as glucosyl hesperidin, because of the higher bioavailability in comparison to the regular hesperidin compound. Biochemical analyses (glucose, triglycerides, cholesterol total, HDL-C) were determined using commercial kits (Labtest, Brazil) by Technicon RAXT chemistry analyzer (Bayer Diagnostic). LDL-C was determined according to Friedewald et al. [19]. Reagents for lipid hydroperoxide and antioxidant substances (TBARS and DPPH) were obtained from Sigma-Aldrich.

\section{Animals and experimental groups}

Male rats Wistar, 12 weeks old, 300-450 g, were maintained in collective cages ( 5 rats $/$ cage, $350 \mathrm{~cm}^{2} /$ animal, $18 \mathrm{~cm}$ of height) on a normal light/dark cycle in a climate-controlled environment and fed with standard rodent chow diet and water ad libitum. The body weights were determined once a week. This study was approved by Ethics Committee on Animal Research at the University of Franca, Sao Paulo, Brazil (Protocol $n^{\circ}$ 0038/10).

Animals ( $n$ 60) were randomly divided into six groups (n 10), as follow: (1) Negative Control (C): no swimming and no supplement; (2) Positive Control $(\mathrm{CH})$ : no swimming plus hesperidin supplement; (3) Continuous Swimming (CS): continuous swimming and no supplement; (4) Continuous Swimming plus hesperidin (CSH): continuous swimming plus hesperidin supplement; (5) Interval Swimming (IS): interval swimming and no supplement; 6) Interval Swimming plus hesperidin (ISH): interval swimming plus hesperidin supplement.

\section{Hesperidin supplementation}

Groups supplemented with the isolated flavonoid received glucosyl hesperidin diluted in saline $(100 \mathrm{mg} / \mathrm{kg}$ body mass) by gavage for four uninterrupted weeks, thirty minutes before of the animals performed the exercise. The amount of glucosyl hesperidin was adjusted in accordance with the weight of each animal.

\section{Swimming protocols}

The animals were trained on continuous or interval swimming during $50 \mathrm{~min}$ per day for four weeks, after one week of adaptation. Rats swam in square polypropylene tanks (5 rats/tank) filled with water $(40 \mathrm{~cm}$ depth) at $27^{\circ} \mathrm{C}$. They were randomly divided in 6 groups and 4 of the groups were subjected to swimming in either of two ways: continuous swimming or interval swimming. Continuous swimming was characterized by cyclical and uninterrupted movements between the arms and legs, using a predominance of the aerobic energy for 50 minutes, carrying a weight equal to $5 \%$ of their body in the first week, gradually progressing to 6,7 and $8 \%$ on the second, third and fourth week [3]. Interval swimming training was performed for a 50 min total period, characterized by brief periods of high-intensity exercise $(60 \mathrm{~s})$ following by rest periods (120 s) on a submersed 
platform, using a predominance of anaerobic energy, carrying a weight equal to $10 \%$ of their body in the first week, gradually progressing to 15,20 and $25 \%$ on the second, third and fourth week. This protocol was adapted from Oliveira et al. [20].

\section{Biochemical analysis}

One day after the experimental period the animals, fasted for $12 \mathrm{~h}$, were decapitated by guillotine, the blood was collected and centrifuged to obtain serum, which was stored at $-20^{\circ} \mathrm{C}$. Serum glucose, total cholesterol, HDL-C and triglycerides were determined by commercial kits (Labtest, Brazil).

\section{Lipid hydroperoxide (TBARS assay)}

Thiobarbituric acid-reactive substances (TBARS) assay was used to determinate the lipid peroxidation of the animals' serum $[21,22]$. Two hundred $\mathrm{mL}$ of MDA standard $(0 ; 1.25 ; 1.88 ; 2.50 ; 3.13 ; 3.75 ; 6.25$ e $12.50 \mathrm{M})$ and serum sample were mixed with $200 \mu \mathrm{L}$ of SDS and then $500 \mu \mathrm{L}$ of staining reagent $(5.3 \mathrm{mg} / \mathrm{mL}$ of TBA diluted in acetic acid $20 \%, \mathrm{pH} 3.5$ ) were vortexed and incubated at $100^{\circ} \mathrm{C}$ for $60 \mathrm{~min}$, and cooled on ice for $10 \mathrm{~min}$. The standards and samples were centrifuged at 10,000 rpm for $10 \mathrm{~min}$, and the absorbance of the supernatant was determined at $532 \mathrm{~nm}$. TBARS concentration was based on the molar extinction coefficient of malondialdehyde.

\section{Antioxidant capacity (DPPH assay)}

Antioxidant substances of the serum were determined by 2,2-diphenyl-1-picrylhydrazyl (DPPH) radical assay $[22,23]$. Protein from serum samples $(200 \mu \mathrm{L})$ was removed with acetonitrile $(200 \mu \mathrm{L})$. Serum supernatant (without protein) was mixed with $970 \mu \mathrm{L}$ of $\mathrm{CH}_{3} \mathrm{OH}$ and $5 \mu \mathrm{L}$ of DPPH (10 mM in methanol), and rested at room temperature for $20 \mathrm{~min}$, and centrifuged for $10 \mathrm{~min}$ at $10,000 \mathrm{rpm}$ at $4^{\circ} \mathrm{C}$. Absorbance of the supernatant was determined at $517 \mathrm{~nm}$.

\section{Statistical analyses}

Data were presented as means \pm SD. Statistical analyses were done by Sigma Stat 3.1 software. Statistical comparisons of the groups were made by ANOVA One Way, followed by post hoc Tukey test for parameters with normal distribution, tested by Kolmogorov-Smirnov, or Student-Newman-Keuls for non-normal data. $P$ value less than 0.05 was considered significant.

\section{Results}

\section{Body weight and weight gain during the experimental} period

There was no statistical difference in initial body weight, final body weight and weight gain between $\mathrm{C}$ and $\mathrm{CH}$ groups, and among the swimming groups, with or without hesperidin (CS, IS, CSH, ISH). But, the animals submitted to swimming (CS, IS, CSH, ISH) showed higher final body weight and weight gain in comparison to the animals without swimming ( $\mathrm{C}$ and $\mathrm{CH})(\mathrm{P}<.05)($ Table 1$)$.

\section{Glucose}

There was a continuous decline of the serum glucose levels from the negative control group to the interval swimming group, as follow: negative control $(\mathrm{C})>$ positive control $(\mathrm{CH})>$ continuous swimming $(\mathrm{CS})>$ continuous swimming + hesperidin $(\mathrm{CSH})>$ interval swimming (IS) > interval swimming + hesperidin (ISH); suggesting a combined effect of hesperidin with swimming on the serum glucose. Statistically, glucose levels are higher for the $\mathrm{C}$ group, and lower for the ISH group, and all other groups with interval values (Table 2).

\section{Triglycerides}

A 13\% reduction of serum triglyceride levels was observed in the $\mathrm{CH}$ group compared to the $\mathrm{C}$ group. Among the exercised animals, with or without hesperidin (CS, CSH, IS, ISH), there were no observed differences on the triglyceride levels (Table 2).

\section{Total cholesterol and LDL-C}

There was a decrease in serum total cholesterol levels of $15 \%$ in the $\mathrm{CH}$ group compared to the $\mathrm{C}$ group. The same response it was observed in the ISH group compared to its control IS $(-15 \%)$ and in the CSH test related to its control CS (-11\%) (Table 2). LDL-C levels were $52 \%$ lower in $\mathrm{CH}$ animals than in the $\mathrm{C}$ group. Similarly, LDL-C was $63 \%$ and $42 \%$ lower in the CSH and ISH groups, respectively than in their controls CS and IS (Table 2). These results follow the same trend found for total cholesterol, showing a markedly beneficial effect of hesperidin on the cholesterol metabolism.

\section{HDL-C}

$\mathrm{CH}$ animals had high levels of blood serum HDL-C (35\%) compared to the $\mathrm{C}$ group, while CS, IS, CSH and ISH also showed increased levels of HDL-C, suggesting that both hesperidin and exercise had a positive effect on HDL-C (Table 2).

\section{Lipid hydroperoxide (TBARS assay)}

There was a marked increase of lipid peroxidation (around 60\%) observed in IS rats in comparison to all groups. This result suggests that the intensity of the interval exercise promoted a higher oxidative stress, but this effect was attenuated by the hesperidin, as we observed in the ISH group (Table 2). 
Table 1 Body weight of rats submitted to continuous or interval swimming with or without supplement

\begin{tabular}{|c|c|c|c|c|c|c|}
\hline \multirow[t]{2}{*}{ Body weight } & \multicolumn{6}{|c|}{ Group name ${ }^{\#}$} \\
\hline & C & $\mathrm{CH}$ & CS & $\mathrm{CSH}$ & IS & ISH \\
\hline (n) & (10) & (10) & (10) & (10) & (10) & (10) \\
\hline Initial, g & $408 \pm 8.5$ & $413 \pm 4.1$ & $404 \pm 7.7$ & $409 \pm 16$ & $413 \pm 13$ & $405 \pm 4.1$ \\
\hline Final, g & $460 \pm 19^{a}$ & $464 \pm 9.8^{a}$ & $428 \pm 7.6^{b}$ & $434 \pm 19^{b}$ & $435 \pm 7.8^{b}$ & $427 \pm 11^{b}$ \\
\hline Weight Gain, g & $52.0 \pm 13.4^{a}$ & $51.4 \pm 12.2^{\mathrm{a}}$ & $24.0 \pm 11.6^{b}$ & $25.3 \pm 17.0^{b}$ & $21.8 \pm 13.9^{b}$ & $22.0 \pm 18.2^{b}$ \\
\hline
\end{tabular}

\section{Antioxidant capacity (DPPH assay)}

Blood serum antioxidant capacity was over 2.8-fold higher in CSH compared to CS, but between the IS and ISH groups no difference was observed (Table 2).

\section{Discussion}

Exercise training intervention is a low-risk conduct that has been designed as adjuvant treatment for chronic illnesses for many decades, but the combination of regular exercise with bioactive compounds to reduce chronic diseases risk factors has been a recent approach suggested in the literature [24,25]. This study tested whether continuous or interval swimming in addition to hesperidin supplementation in rats can improve biochemical and oxidative stress parameters related to chronic diseases.

The findings of the current investigation have shown that hesperidin supplementation in addition to continuous swimming (CSH) or interval swimming (HSE) improved biochemical and oxidative biomarkers in rats. Swimming training by itself, CS and IS groups, or in association with hesperidin, $\mathrm{CSH}$ and $\mathrm{HSH}$ groups, during four weeks improved glucose metabolism, decreased total cholesterol, LDL-C and triglycerides, and increased HDL-C. Furthermore, there was also an enhancement in the antioxidant capacity in the continuous swimming with hesperidin supplement, CSH group. Supplementation with hesperidin did not affect gain weight of rats during the 4-week period, but swimming training, continuous or interval, was an important factor in reducing the weight gain of all trained groups, suggesting that energy expenditure by exercise was the key factor to maintaining body weight [26].

Serum glucose concentration was significantly decreased when the animals were treated with hesperidin, whether associated with swimming or not, $\mathrm{CSH}$, ISH and $\mathrm{CH}$. Recent reviews have shown that regular exercise, continuous or interval, reduced serum glucose by improving insulin sensitivity [27,28], and high intense aerobic exercise induces an improvement of glucose control and adaptation in skeletal muscle [29]. According to the author, blood glucose was reduced by $13 \%$ over the 24 -h period following training, and the postprandial glucose spikes were also reduced for several days afterwards. A recent study with rats that underwent interval swimming showed higher production of the glucose transporter GLUT-4, which is a determining factor for the transport and glucose uptake [30]. Moreover, hesperidin supplementation has important hypoglycemic effects by modulation of gene expression of hepatic enzymes such as glucokinase and glucose-6-fosfatase which are involved in the final step of catalyzing the gluconeogenesis and glycogenolysis, thus playing a role in regulating the homeostatic plasma glucose [31]. Others [32] have shown that isolated hesperidin in rats increased significantly the number of GLUT-2 and GLUT-4 carriers enhancing

Table 2 Biochemical biomarkers of rats submitted to continuous or interval swimming with or without supplement

\begin{tabular}{lcccccc}
\hline Group name $^{\#}$ & $\mathbf{C}$ & $\mathbf{C H}$ & CS & CSH & IS & ISH \\
\hline (n) & $(10)$ & $(10)$ & $(10)$ & $(10)$ & $(10)$ & $(10)$ \\
\hline Glucose, $\mathrm{mg} / \mathrm{dL}$ & $93.9 \pm 4.4^{\mathrm{a}}$ & $91.2 \pm 2.5^{\mathrm{ab}}$ & $88.2 \pm 2.5^{\mathrm{ab}}$ & $85.6 \pm 3.9^{\mathrm{bc}}$ & $81.5 \pm 6.4^{\mathrm{c}}$ & $75.3 \pm 5.7^{\mathrm{d}}$ \\
\hline Triglycerides, $\mathrm{mg} / \mathrm{dL}$ & $147 \pm 15^{\mathrm{a}}$ & $126 \pm 13.1^{\mathrm{b}}$ & $122 \pm 17^{\mathrm{b}}$ & $125 \pm 7.7^{\mathrm{b}}$ & $115 \pm 19^{\mathrm{b}}$ & $108 \pm 12^{\mathrm{b}}$ \\
\hline Cholesterol, $\mathrm{mg} / \mathrm{dL}$ & $140 \pm 22^{\mathrm{ab}}$ & $118 \pm 9.7^{\mathrm{c}}$ & $120 \pm 17^{\mathrm{c}}$ & $106 \pm 7.1^{\mathrm{d}}$ & $146 \pm 11.1^{\mathrm{a}}$ & $125 \pm 10^{\mathrm{b}}$ \\
\hline $\mathrm{LDL}-\mathrm{C}, \mathrm{mg} / \mathrm{dL}$ & $64.9 \pm 15.6^{\mathrm{a}}$ & $31.1 \pm 14.4^{\mathrm{b}}$ & $31.2 \pm 17.9^{\mathrm{b}}$ & $11.8 \pm 8.3^{\mathrm{c}}$ & $55.2 \pm 10.4^{\mathrm{a}}$ & $32.6 \pm 10.1^{\mathrm{b}}$ \\
\hline HDL-C, $\mathrm{mg} / \mathrm{dL}$ & $45.4 \pm 6.3^{\mathrm{b}}$ & $61.2 \pm 5.2^{\mathrm{a}}$ & $63.9 \pm 4.5^{\mathrm{a}}$ & $72.0 \pm 8.1^{\mathrm{a}}$ & $68.2 \pm 4.7^{\mathrm{a}}$ & $70.6 \pm 4.9^{\mathrm{a}}$ \\
\hline TBARS, $\mu \mathrm{M}$ & $1.30 \pm 0.45^{\mathrm{a}}$ & $1.08 \pm 0.31^{\mathrm{a}}$ & $1.24 \pm 0.29^{\mathrm{a}}$ & $1.34 \pm 0.18^{\mathrm{a}}$ & $2.23 \pm 1.37^{\mathrm{b}}$ & $1.23 \pm 0.33^{\mathrm{a}}$ \\
\hline DPPH, \% reduction & $25.2 \pm 4.5^{\mathrm{b}}$ & $22.4 \pm 3.3^{\mathrm{b}}$ & $9.9 \pm 3.9^{\mathrm{a}}$ & $28.0 \pm 3.6^{\mathrm{c}}$ & $16.4 \pm 1.5^{\mathrm{b}}$ & $15.0 \pm 13.4^{\mathrm{b}}$ \\
\hline
\end{tabular}

${ }^{\#} \mathrm{C}$ negative control, $\mathrm{CH}$ positive control, CS continuous swimming, CSH continuous swimming + hesperidin, IS interval swimming, ISH interval swimming + hesperidin. Results are expressed as mean \pm SD.

$a, b, c, d$ Statistical differences among groups, indicated by different letters, were tested by Anova One Way, followed by Tukey test for glucose, triglycerides, cholesterol, LDL-C, HDL-C, DPPH, and Student Newman-Keuls for TBARS $(P<0.05)$. 
cellular signaling glucose and consequently reducing insulin resistance.

Increased levels of physical activity stimulate favorable changes on the levels of circulating lipoproteins, lowering the risks of metabolic disorders such as dyslipidemias, metabolic syndrome and diabetes [5-7]. These changes can vary according to the quantity and intensity of the training, which can decrease cholesterol and triglyceride levels and increase HDL-C $[33,34]$, although a significant increase of HDL-C was more common with high-intensity resistance exercise [35]. On the other hand, citrus flavonoids such as hesperidin and naringin, chemically isolated or from citrus fruits and juices, have been associated with lower levels of LDL-C and triglycerides in humans [36] and animals $[37,38]$. Since the association between exercise training and hesperidin supplementation had not yet been addressed we investigated whether rats, submitted to swimming training alone (CS and IS) and in combination with hesperidin supplementation ( $\mathrm{CSH}$ and ISH), would show increased beneficial effects on the lipid and lipoproteins metabolism.

In this study we observed that $\mathrm{CH}$ rats had a reduced level of serum triglycerides, suggesting that hesperidin is able to decrease the synthesis or catabolism of triglycerides-rich lipoproteins. A previous study [36] found that hesperidin supplement in subjects with hypertriglyceridemia ( $>150 \mathrm{mg} / \mathrm{dL}$ ) dropped serum triglycerides, presumably because of the increase in triglyceride rich lipoproteins catabolism. On the other hand, it was shown [39] that hesperitin, the aglycon form of hesperidin, inhibited VLDL secretion in vivo and in vitro by inhibition of microsomal triglycerides transfer protein (MTP) activity, transcription of HMG CoA-reductase, ACAT activity and synthesis of Apo B, causing a $70 \%$ reduction in the secretion of hepatic ApoB-100/VLDL. Therefore, from these previous studies we can deduce that hesperidin was reducing both synthesis and catabolism of triglycerides. Except for the negative control group, the others $(\mathrm{CH}, \mathrm{CS}$, IS, $\mathrm{CSH}, \mathrm{ISH}$ ) showed lower levels of triglycerides, which suggested that hesperidin supplementation and swimming improved triglyceride metabolism, although the individual effects from exercise and supplement were not additive.

Regarding total cholesterol and LDL-C levels, we observed a marked reduction promoted by hesperidin in the $\mathrm{CH}, \mathrm{CSH}$ and $\mathrm{ISH}$ groups in comparison to their controls (C, CS, IS) without supplementation. This result is corroborated by previous studies which showed that hesperidin lower plasma and liver cholesterol by inhibition of HMG CoA-reductase, ACAT and secretion of Apo B [39-41]. In addition hesperidin increased expression of the gene encoding the LDL receptor and its specific metabolism [42].
A recent study showed that either high-intensity or moderate-intensity exercise training reduced cardiovascular risk in rats with the metabolic syndrome. The authors found that both exercises improved endothelial function and blood pressure, increased HDL cholesterol, and reduced blood glucose. Also, the exercise reduced the impact of the metabolic syndrome and that the magnitude of the effect depends on exercise intensity [43]. Another study reported that acute resistance exercise in moderate or high intensity, as aerobic exercise, may have antiatherogenic effects, particularly throughout lipid profile modulation [44]. We observed in our study a concomitant increase of HDL-C on swimming groups (CS, IS) and on hesperidin-supplement groups $(\mathrm{CH}$, $\mathrm{CSH}, \mathrm{ISH})$, but the effects were not additive.

HDL-C is a fraction of lipoprotein that carry cholesterol into the blood and is responsible for facilitating the reverse transport of cholesterol from peripheral tissues to the liver, where it is catabolized and excreted, and its function is recognized as antiatherogenic [45]. Although there are some controversies, it is well known that HDL$\mathrm{C}$ levels is generally responsive to aerobic training and increases in a dose-dependent manner with increased energy expenditure [5]. Additionally the exercise intensity and duration are also associated with positive changes in the levels of HDL-C [43].

Because of the benefits that have been reported, regular physical exercise has been adopted as part of an overall strategy to normalize lipid profiles and to improve cardiovascular health [46]. However, it is questionable whether all physical exercise, despite the beneficial effects on lipid profile, might really be safe. It has been reported that exhaustive exercise, such as swimming, induces oxidative stress due to excessive oxygen reception and elevated production of ROS [47]. On the other hand, moderate regular exercise can have positive effects by upregulating the activities of antioxidant enzymes thereby reducing oxidative stress [48].

Regarding the oxidative stress and exercise, is well establish that prolonged or high-intensity exercises, such as interval training, increases the production of oxygen free radicals and lipid peroxidation which are related to oxidative damage to macromolecules in blood and skeletal muscle $[49,50]$. Therefore we evaluated the protective role of hesperidin, as an antioxidant compound, in continuous and interval exercise. No changes were observed in lipid peroxidation in the $\mathrm{C}, \mathrm{CH}, \mathrm{CS}, \mathrm{CSH}$ groups, whereas there was a reduction of over $50 \%$ of lipid peroxidation triggered by the interval exercise (IS) with hesperidin supplementation in the ISH group. Previous study also attributed to hesperidin and naringin, and not to the vitamin $C$ in orange juice, the effect of neutralizing the oxidative stress resulting from the ingestion of a pro-inflammatory high-fat, high- 
carbohydrate meal [51]. The continuous exercise increased the oxidative stress in animals that performed continuous swimming exercise (CS), however, the hesperidin supplement increased markedly (over 100\%) the antioxidant capacity in the $\mathrm{CSH}$ group. Antioxidant capacity by hesperidin on other groups was unchanged (C, CH, CS, IS, ISH).

The antioxidant effects of the flavonoids quercetin [52] and eriocitrin [9] were also observed in swimming and running protocols, endorsing the idea that those flavonoids can prevent oxidative damage caused by exercise in the brain and liver, respectively. Another study attributed to isolated antioxidant compounds from legumes the capacity in inhibit xanthine oxidase (XO), the main enzyme related to the generation of free radicals during exercise [53], revealing beneficial health impacts as natural antioxidants of therapeutic interest, i.e. dietary [54]. Elsewhere the antioxidant activities of hesperidin and its metabolites have been shown by the increase of antioxidant enzymes and the decrease of oxidative stress $[14,55]$.

\section{Conclusions}

In summary, the findings of the present study have shown that hesperidin supplementation per se or in combination with swimming exercise protocols, continuous and interval, potentiates improvement of the biochemical profile and antioxidant biomarkers evidencing that the use of citrus flavonoids may be beneficial to reduce risk factors for metabolic and cardiovascular diseases. Moreover, hesperidin supplementation, in conjunction with continuous swimming, presented hypolipidemic effects and could be useful as an antioxidative compound to protect against oxidative damages during this type of exercise; on the other hand, hesperidin plus interval swimming exercise can help reduce increased levels of glucose in the blood serum.

\footnotetext{
Abbreviations

ACAT: Acetyl-Coenzyme A acetyltransferase; Apo B: Apolipoprotein B; $\mathrm{C}$ : Negative control group, no swimming and no supplement; $\mathrm{CH}$ : Positive control group, no swimming plus hesperidin supplement; $\mathrm{CH}_{3} \mathrm{OH}$ : Methanol; CS: Continuous swimming group, continuous swimming and no supplement; CSH: Continuous swimming plus hesperidin group, continuous swimming plus hesperidin supplement; DPPH: 2,2-diphenyl-1-picrylhydrazyl; GLUT-2: Glucose transporter type 2; GLUT-4: Glucose transporter type 4; HDL-: High density lipoprotein-cholesterol; HMG CoA-reductase: 3-hydroxy-3methyl-glutaryl-CoA reductase; IS: Interval swimming group, interval swimming and no supplement; ISH: Interval swimming plus hesperidin group, interval swimming plus hesperidin supplement; LDL-C: Low density lipoprotein-cholesterol; MDA: Malondialdehyde; MTP: Microsomal triglycerides transfer protein; SDS: Sodium dodecyl sulphate;

TBA: Thiobarbituric acid; TBARS: Thiobarbituric acid-reactive substances.
}

\section{Competing interests}

The results of the present study do not constitute endorsement of any products by the authors or by ACMS or other organizations. The authors declare that we do not have any conflicts of interest and that the source of funding is independent of the objectives and results found in this study.

\section{Authors' contributions}

The authors David de Oliveira and Grace Dourado participated in the collection of data, biochemical evaluation and statistical analysis. The interpretation of data and writing of the text were accomplished by all authors, including Thais Cesar, who was the mentor of this work. All authors have seen and approved the final version of this paper.

\section{Acknowledgements}

We are grateful to the Conselho Nacional de Desenvolvimento Científico e Tecnológico (CNPq), Brazil, for the scholarship to Grace Dourado. We also thank to Hayashibara, Japan, for providing glucosyl hesperidin for the experiments.

Received: 4 October 2012 Accepted: 18 May 2013 Published: 24 May 2013

\section{References}

1. Thompson PD, Buchner D, Pina IL, Balady GJ, et al: American heart association council on clinical cardiology subcommittee on exercise, rehabilitation, and prevention; American heart association council on nutrition, physical activity, and metabolism subcommittee on physical activity. Exercise and physical activity in the prevention and treatment of atherosclerotic cardiovascular disease: a statement from the council on clinical cardiology (subcommittee on exercise, rehabilitation, and prevention) and the council on nutrition, physical activity, and metabolism (subcommittee on physical activity). Circulation 2003, 107(24):3109-3116.

2. Jeppesen J, Kiens B: Regulation and limitations to fatty acid oxidation during exercise. J Physiol 2012, 590:1059-1068.

3. de Araujo GG, Papoti M, Dos Reis IG, de Mello MA, Gobatto CA: Physiological responses during linear periodized training in rats. Eur $J$ Appl Physiol 2012, 112(3):839-852.

4. Rogatto GP, Luciano E: Effects of high intensity training on glucose metabolism. Rev Bras Ativ Fís Saúde 2001, 6:39-6.

5. Durstine JL, Grandjean PW, Cox CA, Thompson PD: Lipids, lipoproteins, and exercise. J Cardiopulm Rehabil 2002, 22(6):385-398

6. Botezelli JD, Cambri LT, Ghezzi AC, Dalia RA, M Scariot PP, Ribeiro C, Voltarelli FA, Mello MA: Different exercise protocols improve metabolic syndrome markers, tissue triglycerides content and antioxidant status in rats. Diabetol Metab Syndr. 2011, 3:35

7. Frajacomo FT, Demarzo MM, Fernandes CR, Martinello F, Bachur JA, Uyemura SA, Perez SE, Garcia SB: The effects of high-intensity resistance exercise on the blood lipid profile and liver function in hypercholesterolemic hamsters. Appl Physiol Nutr Metab 2012, 37(3):448-454

8. Sachdev S, Davies KJ: Production, detection, and adaptive responses to free radicals in exercise. Free Radic Biol Med 2008, 44(2):215-223.

9. Minato K, Miyake $Y$, Fukumoto S, Yamamoto K, Kato Y, Shimomura Y, Osawa $\mathrm{T}$ : Lemon flavonoid, eriocitrin, suppresses exercise-induced oxidative damage in rat liver. Life Sci 2003, 72(14):1609-1616.

10. Lyall KA, Hurst SM, Cooney J, Jensen D, Lo K, Hurst RD, Stevenson LM: Short-term blackcurrant extract consumption modulates exerciseinduced oxidative stress and lipopolysaccharide-stimulated inflammatory responses. Am J Physiol Regul Integr Comp Physiol 2009, 297(1):R70-R81.

11. Kurowska EM, Spence JD, Jordan J, Wetmore S, Freeman DJ, Piché LA, Serratore P: HDL-cholesterol-raising effect of orange juice in subjects with hypercholesterolemia. Am J Clin Nutr 2000, 72(5):1095-1100.

12. Kim HK, Jeong TS, Lee MK, Park YB, Choi MS: Lipid-lowering efficacy of hesperetin metabolites in high-cholesterol fed rats. Clin Chim Acta 2003, 327(1-2):129-137.

13. Gorinstein S, Caspi A, Libman I, Leontowicz H, Leontowicz M, Tashma Z,

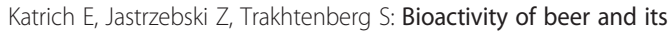
influence on human metabolism. Int J Food Sci Nutr 2007, 58(2):94-107.

14. Kim HJ, Jeon SM, Lee MK, Cho YY, Kwon EY, Lee JH, Choi MS: Comparison of hesperetin and its metabolites for cholesterol-lowering and antioxidative efficacy in hypercholesterolemic hamsters. J Med Food 2010, 13(4):808-814.

15. Miyake $Y$, Minato $K$, Fukumoto S, Yamamoto K, Oya-Ito T, Kawakishi S, Osawa T: New potent antioxidative hydroxyflavanones produced with Aspergillus saitoi from flavanone glycoside in citrus fruit. Biosci Biotechnol Biochem 2003, 67(7):1443-1450. 
16. Cureton KJ, Tomporowski PD, Singhal A, Pasley JD, Bigelman KA, Lambourne K, Trilk JL, McCully KK, Arnaud MJ, Zhao Q: Dietary quercetin supplementation is not ergogenic in untrained men. J Appl Physiol 2009 107(4):1095-1104.

17. Di Giacomo C, Acquaviva R, Sorrenti V, Vanella A, Grasso S, Barcellona ML, Galvano F, Vanella L, Renis M: Oxidative and antioxidant status in plasma of runners: effect of oral supplementation with natural antioxidants. $J$ Med Food 2009, 12(1):145-150.

18. Aptekmann NP, Cesar TB: Orange juice improved lipid profile and blood lactate of overweight middle-aged women subjected to aerobic training. Maturitas 2010, 67(4):343-347.

19. Friedewald WT, Levy RI, Fredrickson DS: Estimation of the concentration of low-density lipoprotein cholesterol in plasma, without use of the preparative ultracentrifuge. Clin Chem 1972, 18(6):499-502.

20. Oliveira CAM, Rogatto GP, Luciano E: Effects of high intensity physical training on the leukocytes of diabetic rats. Rev Bras Med Esporte 2002, 8(6):219-224.

21. Yagi K: Simple assay for the level of total lipid peroxides in serum or plasma. Methods Mol Biol 1998, 108:101-106.

22. Nasser ALM, Dourado GKZS, Manjate DA, Carlos IZ, et al: Oxidative stress evaluation on the blood of regular consumers of orange juice. Rev Ciênc Farm Basica Apl. 2011, 32:275-279.

23. Chrzczanowicz J, Gawron A, Zwolinska A, de Graft-Johnson J, Krajewski W, Krol M, Markowski J, Kostka T, Nowak D: Simple method for determining human serum 2,2-diphenyl-1-picryl-hydrazyl (DPPH) radical scavenging activity - possible application in clinical studies on dietary antioxidants. Clin Chem Lab Med 2008, 46(3):342-349.

24. Lee J, Cho HS, Kim DY, Cho JY, Chung JS, Lee HK, Seong NH, Kim WK: Combined effects of exercise and soy isoflavone diet on paraoxonase, nitric oxide and aortic apoptosis in ovariectomized rats. Appetite 2012, 58(2):462-469

25. O'Fallon KS, Kaushik D, Michniak-Kohn B, Dunne CP, Zambraski EJ, Clarkson PM: Quercetin Does Not Attenuate Changes in Markers of Muscle Function or Inflammation after Eccentric Exercise. Int I Sport Nutr Exerc Metab 2012. Jul 4. [Epub ahead of print].

26. Botezelli JD, Cambri LT, Ghezzi AC, Dalia RA, Scariot PP M, Ribeiro C, Voltarelli FA, Mello MA: Different exercise protocols improve metabolic syndrome markers, tissue triglycerides content and antioxidant status in rats. Diabetol Metab Syndr. 2011, 19:3-35.

27. Kessler HS, Sisson SB, Short KR: The potential for high-intensity interval training to reduce cardiometabolic disease risk. Sports Med 2012, 42(6):489-509.

28. Colberg SR: Physical activity: the forgotten tool for type 2 diabetes management. Front Endocrinol (Lausanne). 2012, 3:70.

29. Little JP, Gillen JB, Percival ME, Safdar A, Tarnopolsky MA, Punthakee Z, Jung ME, Gibala MJ: Low-volume high-intensity interval training reduces hyperglycemia and increases muscle mitochondrial capacity in patients with type 2 diabetes. J Appl Physiol 2011, 111(6):1554-60.

30. Fujimoto E, Machida S, Higuchi M, Tabata I: Effects of nonexhaustive bouts of high-intensity intermittent swimming training on GLUT-4 expression in rat skeletal muscle. J Physiol Sci 2010, 60(2):95-101.

31. Liu L, Shan S, Zhang K, Ning ZQ, Lu XP, Cheng YY: Naringenin and hesperetin, two flavonoids derived from Citrus aurantium up-regulate transcription of adiponectin. Phytother Res 2008, 22(10):1400-3.

32. Jung UJ, Lee MK, Park YB, Kang MA, Choi MS: Effect of citrus flavonoids on lipid metabolism and glucose-regulating enzyme mRNA levels in type-2 diabetic mice. Int J Biochem Cell Biol 2006, 38(7):1134-45.

33. Fahlman MM, Boardley D, Lambert CP, Flynn MG: Effects of endurance training and resistance training on plasma lipoprotein profiles in elderly women. J Gerontol A Biol Sci Med Sci 2002, 57(2):B54-60.

34. Kelley GA, Kelley KS, Roberts S, Haskell W: Comparison of aerobic exercise, diet or both on lipids and lipoproteins in adults: a meta-analysis of randomized controlled trials. Clin Nutr 2012, 31(2):156-67.

35. Hill S, Bermingham MA, Knight PK: Lipid metabolism in young men after acute resistance exercise at two different intensities. J Sci Med Sport 2005, 8(4):441-5.

36. Miwa Y, Mitsuzumi H, Sunayama T, Yamada M, Okada K, Kubota M, Chaen $H$, Mishima $Y$, Kibata M: Glucosyl hesperidin lowers serum triglyceride level in hypertriglyceridemic subjects through the improvement of very low-density lipoprotein metabolic abnormality. J Nutr Sci Vitaminol 2005, 51(6):460-70.
37. Ohtsuki K, Abe A, Mitsuzumi H, Kondo M, Uemura K, Iwasaki Y, Kondo Y: Glucosyl hesperidin improves serum cholesterol composition and inhibits hypertrophy in vasculature. J Nutr Sci Vitaminol (Tokyo). 2003, 49(6):447-50.

38. Selvaraj P, Pugalendi KV: Efficacy of hesperidin on plasma, heart and liver tissue lipids in rats subjected to isoproterenol-induced cardiotoxicity. Exp Toxicol Pathol 2012, 64(5):449-52.

39. Wilcox LJ, Borradaile NM, de Dreu LE, Huff MW: Secretion of hepatocyte apoB is inhibited by the flavonoids, naringenin and hesperetin, via reduced activity and expression of ACAT2 and MTP. J Lipid Res 2001, 42(5):725-34.

40. Bok SH, Lee SH, Park YB, Bae KH, Son KH, Jeong TS, Choi MS: Plasma and hepatic cholesterol and hepatic activities of 3-hydroxy-3-methyl-glutarylCoA reductase and acyl CoA: cholesterol transferase are lower in rats fed citrus peel extract or a mixture of citrus bioflavonoids. J Nutr 1999, 129(6):1182-5.

41. Choi GS, Lee S, Jeong TS, Lee MK, Lee JS, Jung UJ, Kim HJ, Park YB, Bok SH, Choi MS: Evaluation of hesperetin 7-O-lauryl ether as lipid-lowering agent in high-cholesterol-fed rats. Bioorg Med Chem 2004, 12(13):3599-605.

42. Morin B, Nichols LA, Zalasky KM, Davis JW, Manthey JA, Holland LJ: The citrus flavonoids hesperetin and nobiletin differentially regulate low density lipoprotein receptor gene transcription in HepG2 liver cells. J Nutr 2008, 138(7):1274-81.

43. Haram PM, Kemi OJ, Lee SJ, Bendheim MØ, Al-Share QY, Waldum HL, Gilligan LJ, Koch LG, Britton SL, Najjar SM, Wisløff U: Aerobic interval training vs. continuous moderate exercise in the metabolic syndrome of rats artificially selected for low aerobic capacity. Cardiovasc Res 2009, 81(4):723-32.

44. Lira FS, Carnevali LC Jr, Zanchi NE, Santos RV, Lavoie JM, Seelaender M: Exercise intensity modulation of hepatic lipid metabolism. J Nutr Metab. 2012, 2012:809576. Epub 2012 Apr 2.

45. Rothblat GH, Phillips MC: High-density lipoprotein heterogeneity and function in reverse cholesterol transport. Curr Opin Lipidol 2010, 21(3):229-38.

46. Grandjean PW, Crouse SF, Rohack JJ: Influence of cholesterol status on blood lipid and lipoprotein enzyme responses to aerobic exercise. J App/ Physiol 2000, 89(2):472-80.

47. Goto S, Naito H, Kaneko T, Chung HY, Radák Z: Hormetic effects of regular exercise in aging: correlation with oxidative stress. Appl Physiol Nutr Metab 2007, 32(5):948-53.

48. Ji LL: Exercise at old age: does it increase or alleviate oxidative stress? Ann N Y Acad Sci 2001, 928:236-47.

49. Powers SK, Nelson WB, Hudson MB: Exercise-induced oxidative stress in humans: cause and consequences. Free Radic Biol Med 2011, 51(5):942-50.

50. Fogarty MC, Hughes CM, Burke G, Brown JC, Trinick TR, Duly E, Bailey DM, Davison GW: Exercise-induced lipid peroxidation: Implications for deoxyribonucleic acid damage and systemic free radical generation. Environ Mol Mutagen 2011, 52(1):35-42.

51. Ghanim H, Mohanty P, Pathak R, Chaudhuri A, Sia CL, Dandona P: Orange juice or fructose intake does not induce oxidative and inflammatory response. Diabetes Care 2007, 30(6):1406-11.

52. Haleagrahara N, Radhakrishnan A, Lee N, Kumar P: Flavonoid quercetin protects against swimming stress-induced changes in oxidative biomarkers in the hypothalamus of rats. Eur J Pharmacol 2009, 621(1-3):46-52

53. Gomez-Cabrera MC, Borrás C, Pallardó FV, Sastre J, Ji LL, Viña J: Decreasing xanthine oxidase-mediated oxidative stress prevents useful cellular adaptations to exercise in rats. J Physiol 2005, 567(Pt 1):113-20.

54. Spanou C, Veskoukis AS, Kerasioti T, Kontou M, Angelis A, Aligiannis N, Skaltsounis AL, Kouretas D: Flavonoid glycosides isolated from unique legume plant extracts as novel inhibitors of xanthine oxidase. PLOS One 2012, 7(3):e32214

55. Tirkey N, Pilkhwal S, Kuhad A, Chopra K: Hesperidin, a citrus bioflavonoid, decreases the oxidative stress produced by carbon tetrachloride in rat liver and kidney. BMC Pharmacol 2005, 5:2.

\section{doi:10.1186/1550-2783-10-27}

Cite this article as: de Oliveira et al.: Hesperidin associated with continuous and interval swimming improved biochemical and oxidative biomarkers in rats. Journal of the International Society of Sports Nutrition 2013 10:27 